\title{
Article \\ Quantitative Models for Prediction of Cumulative Trauma Disorders Applied to the Maquiladora Industry
}

\author{
Melissa Airem Cázares-Manríquez ${ }^{1}$ (D), Claudia Camargo-Wilson ${ }^{1}$, Ricardo Vardasca ${ }^{2,3,4}{ }^{\mathbb{D}}$, \\ Jorge Luis García-Alcaraz ${ }^{5, * \mathbb{D}}$, Jesús Everardo Olguín-Tiznado ${ }^{1} \mathbb{D}$, Juan Andrés López-Barreras ${ }^{6}$ (D)
} and Blanca Rosa García-Rivera ${ }^{7}$ (D)

check for updates

Citation: Cázares-Manríquez, M.A.; Camargo-Wilson, C.; Vardasca, R.; García-Alcaraz, J.L.; Olguín-Tiznado, J.E.; López-Barreras, J.A.;

\section{García-Rivera, B.R. Quantitative}

Models for Prediction of Cumulative Trauma Disorders Applied to the Maquiladora Industry. Int. J. Environ. Res. Public Health 2021, 18, 3830. https://doi.org/10.3390/ijerph18073830

Academic Editor: Wing-Keung Wong

Received: 23 January 2021

Accepted: 1 April 2021

Published: 6 April 2021

Publisher's Note: MDPI stays neutral with regard to jurisdictional claims in published maps and institutional affiliations.

Copyright: (c) 2021 by the authors Licensee MDPI, Basel, Switzerland This article is an open access article distributed under the terms and conditions of the Creative Commons Attribution (CC BY) license (https:// creativecommons.org/licenses/by/ $4.0 /)$
1 Faculty of Engineering, Arquitecture and Design, Autonomous University of Baja California, Ensenada BC 22860, Mexico; airem.cazares@uabc.edu.mx (M.A.C.-M.); ccamargo@uabc.edu.mx (C.C.-W.); jeol79@uabc.edu.mx (J.E.O.-T.)

2 Faculdade de Engenharia, Universidade do Porto, 4200-465 Porto, Portugal; ricardo.vardasca@fe.up.pt or ricardo.vardasca@islasantarem.pt

3 INEGI, Universidade do Porto, 4200-465 Porto, Portugal

4 ISLA Santarém, 2000-241 Santarém, Portugal

5 Department of Industrial Engineering and Manufacturing, Autonomous University of Ciudad Juarez, Ciudad Juárez CHIH 32310, Mexico

6 Faculty of Chemical Sciences and Engineering, Autonomous University of Baja California, Tijuana BC 22390, Mexico; jalopez@uabc.edu.mx

7 Faculty of Administrative and Social Sciences, Autonomous University of Baja California, Tijuana BC 22390, Mexico; blanca_garcia@uabc.edu.mx

* Correspondence: jorge.garcia@uacj.mx

Abstract: Temperature gradient changes on the surface of the skin or in the middle of the body are signs of a disease. The aim of this study is to develop quantitative models for the prediction of cumulative trauma disorders (CTDs) arising from highly repetitive activities, considering risk factors, such as age, gender, body mass index (BMI), blood pressure (BP), respiratory rate (RR), and heart rate, to prevent injuries in manufacturing factory operators. This research involved 19 individuals from the area of sanding and 14 individuals from the area of tolex in manufacturing factories who had their vital signs and somatometry taken, as well as thermal images of their hands in the dorsal and palmar areas; an evaluation by the OCRA method was also applied. Factors such as BP and heart rate were determined to significantly influence the injuries, but no strong association with BMI was found. Quadratic regression models were developed, the estimates of which were adequately adjusted to the variable $\left(\mathrm{R}^{2}\right.$ and $\mathrm{R}^{2}$ adjusted $\left.>0.70\right)$. When integrating the factors of the OCRA method to the generated models, a better fit was obtained $\left(R^{2}\right.$ and adjusted $\left.R^{2}>0.80\right)$. In conclusion, the participants who present levels out of the normal range in at least one of the factors have high probabilities of developing injuries in their wrists.

Keywords: age; blood pressure; body mass index; carpal tunnel syndrome; cumulative trauma disorder; heart rate; infrared thermography; respiratory rate; gender

\section{Introduction}

Musculoskeletal system disorders (MSDs) refer to health problems in the locomotive system; that is, muscles, tendons, skeleton, cartilage, joints, ligaments, blood vessels, and tendons [1,2]. MSDs are a set of symptoms and injuries (inflammatory or degenerative) of the musculoskeletal system, and are related to the neck, back, and upper and lower extremities of the body [3]. MSDs are the most common occupational diseases in industry. They derive from various causes, and are divided into two categories: those caused by acute trauma, such as slips or falls, and those due to repetitive exposure to a type of physical activity, known as cumulative trauma disorders (CTDs), meaning that these injuries develop over time, which can be as long as weeks, months, or even years of 
propensity to repetitive stress, so that they are not due to a single temporary event, as is the case of the first category, but to various micro-traumas [1,2].

When MSDs are caused by work-related issues, they are called work-related musculoskeletal disorders (WMSDs) [4]. For years, studies have focused on ways to reduce WMSDs. General knowledge of the mechanisms and factors that cause the given ailments, among others, has enabled the development of a series of methods for risk occurrence and identification. WMSDs can be prevented through ergonomic interventions, including optimization of posture and working conditions, muscle and movement training, periodic work breaks, and load-dependent work management, through which the load on the musculoskeletal system can be reduced, thus providing workers with a longer working life [5].

Workers who suffer from this disorder may experience severe pain, which is reflected in a decrease in productivity and quality of work, and can even cause disability, which causes absenteeism from work and leads to increased costs for businesses and for the public health system [2]. Pain caused by musculoskeletal disorders is the second leading cause of disability [6], and, according to the International Labour Organization (ILO), it is estimated that occupational accidents and diseases cause the loss of $4 \%$ of the gross domestic product (GDP), or about $\$ 2.8$ billion in direct and indirect costs.

MSDs occur in different areas of the body, caused by a variety of different types of tasks. In the upper extremities, such as the fingers, hands, wrists, arms, elbows, shoulders, and neck, MSDs can originate from repetitive or lasting static force, leading to tendinitis or nerve entrapment, such as carpal tunnel syndrome (CTS) [2,7-9]. CTS is due to compression of the median nerve inside the carpal tunnel, while flexor tendinitis causes compression of the median nerve by increased pressure in the carpal tunnel due to edema.

Currently, there are several methods that allow us to detect MSDs. For example, CTS is detected by means of palpation tests, such as the Phalen's and Tinel's tests, and electromyography. However, the use of thermal imaging may improve medical diagnosis [10].

Temperature gradient changes (decrease and increase) on the skin surface or in the middle of the body are indicators of disease, allowing the evaluation of changes in metabolism and blood flow, especially in a superficial layer of the skin [10-15]. Several studies indicate that the symmetry of the extremities and torso will not have a temperature difference on the two sides along a dermatome or thermatome of more than $0.30{ }^{\circ} \mathrm{C}$, and of no more than $0.90{ }^{\circ} \mathrm{C}$ on the forearms [16]. The diagnosis of neuromuscular pathology by infrared thermography (IT) is based on the existence of thermal symmetry and asymmetry between normal and abnormal sites $[17,18]$. IT works by measuring the temperature distribution of a surface, which offers several advantages, because it is non-invasive, non-contact, nonradioactive, and painless, and the results are easy to reproduce (thermal imaging); it also has a low operating cost [10,19-21]. A broad range of research has proven the effectiveness of IT in diagnosing CTS [20,21].

Nowadays, CTS is a pathology of great interest in medical research, since it represents one of the greatest occupational health problems of any upper limb disorder [22], and yet, the etiology is not appropriately described [22,23].

Epidemiological studies have been undertaken to identify risk factors for CTS, and the results are contradictory. However, the most consistent factors have been being female [22-29], thirty years or older $[22,23,25,26,28-36]$, having repetitive motor activity, and having a number of systemic diseases, such as diabetes mellitus [10], rheumatoid arthritis [37,38], and hypothyroidism [37,39].

Campillo \& De la Vega [40] developed a predictive model for CTDs by using sensory thermography as the main tool. They sought to determine whether there is a relationship between temperature variability and CTD diagnosis and, at the same time, whether there is a gender difference regarding CTDs. However, the model does not explain the temperature variation over time well. In turn, Márquez Gómez [41] used traditional methods, such as RULA (Rapid Upper Limb Assessment) and OCRA (Occupational Repetitive Action), in combination with statistical techniques for the selection of significant predictor variables 
for the development of predictive models. Grieco [42] reported a logarithmic conversion of the relative exposure (OCRA) and injury indices, with which he constructed a simple linear regression model for risk prediction of WRMSDs. In the same context, Álvarez-Tello et al. [43] developed a predictive model using binary logistic regression and the items of the strain index questionnaire as predictor variables. The aim of this study is to develop quantitative predictive models that integrate risk factors for CTD, such as age, sex, BMI (body mass index), blood pressure (BP), respiratory rate (RR), and heart rate.

\section{Materials and Methods}

\subsection{Recruitment and Selection of Participants}

At first, the target company was approached to explain the purposes of the research and to request approval to apply the project by means of a document expressing the objectives, procedures, and analyses to be carried out, as well as estimated times. Once permission was obtained from the business authorities, the study was initiated based on the clinical procedures established by the company's occupational health department.

Two production areas were assigned, the sanding and tolex areas, which had the highest records for wrist problems among the operators. In the sanding area, the activities of the operators consist of the sanding process of the body, neck, and edges of the wood product using orbital and edge sanders. On the other hand, in the tolex area, the cabinet subassembly and lining process is performed, which includes the activities of vinyl and fabric cutting, gluing, and stapling. Next, each of the areas was visited to learn about their production processes and to determine the experimental space. Afterwards, a questionnaire was given to each operator (a total of 39 persons), designed to select the participants of the study, obtaining their socio-demographic information and health conditions. This phase had an approximate duration of one month, due to the time restriction so as not to affect the daily production goals of the company.

Twenty-three questionnaires were applied in the sanding area and 16 in the tolex area. At the end of the recruitment process, 19 participants were selected from the sanding area (four persons were not selected due to disabilities and diabetes). Sixteen questionnaires were applied in the tolex area, and 14 participants were chosen (one person did not want to participate and another one had epilepsy). One woman and eighteen men participated in the sanding area (average age $=33 \pm 9.7$ years). Six women and eight men participated in the tolex area (average age $=35 \pm 7.45$ years). The experimental sample included a total of 33 people.

Then, the vital signs and somatometry of the chosen participants were recorded, including weight, height, body mass index (BMI), blood pressure (BP), heart rate, and respiratory rate (R.R). The sanding area showed an average BMI $=27 \mathrm{~kg} / \mathrm{m}^{2}, \mathrm{BP} 78 \%$ normal, $13 \%$ high, and $9 \%$ low; $96 \%$ of the participants were right-handed, had an average heart rate of 77.43 beats per minute (BPM), and an RR of 17.63 breaths per minute. In the tolex area, an average BMI of $28.4 \mathrm{~kg} / \mathrm{m}^{2}$, BP $75 \%$ normal, $12.5 \%$ high, and $12.5 \%$ low was recorded. All of the participants in this area were right-handed, and had an average heart rate of $94.18 \mathrm{BPM}$ and an RR of 18.5 breaths per minute.

The selected subjects did not take drugs for the peripheral nervous system (vasodilator, antihypertensive) so as not to interrupt the sympathetic vasoconstrictive response and, therefore, affect their body temperature. Furthermore, they were asked to meet certain criteria in order to take the thermograms listed below. Data collection and thermograms at the company began in February 2019 and ended in June 2019.

A diagram with the measurement methodology appears in Figure 1. 


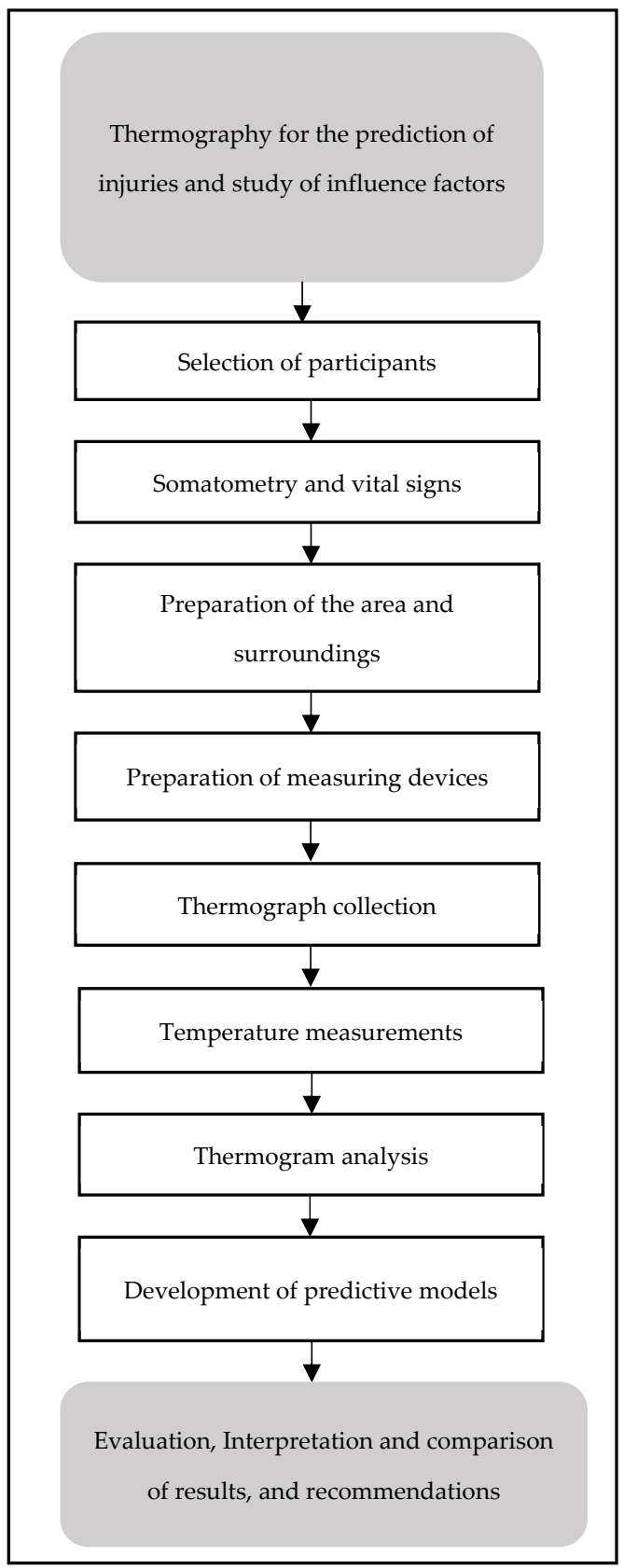

Figure 1. Measurement methodology flowchart.

\subsection{Statement of Ethics}

This study was conducted in accordance with the written consent granted by the company, which was provided verbally to all participants. The protocol was reviewed and approved by the ethics and bioethics committee of the postgraduate department of the Faculty of Engineering, Architecture, and Design of the Autonomous University of Baja California, according to the NOM-035-STPS-2018 Standard.

\subsection{Preliminary Restrictions}

Prior to taking the thermograms and in order to eliminate uncertainties in temperature measurements, the following restrictions were imposed on participants, based on the protocols of Glamorgan [44], Standard Procedures for Infrared Imaging in Medicine [45], and Design and Application of a Protocol for Acquiring and Processing Infrared Images from the Hands [46]. 
- Not to smoke in the hours prior to taking the images (12 hours).

- Not to drink alcoholic beverages in the hours prior to the exam (12 hours).

- Not to drink coffee or tea for several hours before the study (12 hours).

- Preferably, not to eat fatty foods before the analysis.

\subsection{Experimental Protocol}

\subsubsection{Environmental Conditions for the Study}

To avoid vasomotion phenomena, the controlled temperature of the rooms assigned by each area was kept between $23-24^{\circ} \mathrm{C}\left(+/-1{ }^{\circ} \mathrm{C}\right)$. Regarding humidity, its values oscillated between $50-60 \%$, depending on the weather conditions of the region. On days when the humidity of the environment was high, a dehumidifier was required to reduce it to adequate levels. Within the space allocated for the recordings, air drafts on the subjects' hands and lamps or domes above them were avoided during the taking of the thermal images. The participants were asked to uncover their forearm (if necessary), not to wear bracelets, rings, or wristbands, and to remove earrings, glasses, and caps.

\subsubsection{Thermographic Infrared Camera Implementation}

The IT camera used in this study was a FLIR ThermaCAM ${ }^{\mathrm{TM}}$ E25 model, fabricated by FLIR Systems at Boston, MA, USA, with a resolution of $160 \times 120$ pixels, an accuracy of $\pm 2{ }^{\circ} \mathrm{C} / \pm 3.6^{\circ} \mathrm{C}$ for $\pm 2 \%$ of reading, and a spectral range of $7.5-13 \mu \mathrm{m}$. The camera was mounted on a tripod for better handling, with an emissivity of 0.98 , as this is the average emissivity of human skin, and thus avoids errors in temperature measurement. Each time the infrared camera was used, the emissivity was set to this value. The chosen region (Figure 2) was taken for all participants. Before each shot, the camera was kept turned on for 15 minutes to maintain thermal equilibrium with its surroundings. The camera was placed perpendicular to the subject's hand at a minimum distance of $0.601 \mathrm{~m} \mathrm{[46].} \mathrm{For} \mathrm{this}$ study, a distance of two meters was considered. It is worth mentioning that a black surface was placed as a background for the image, contributing to the improvement of the reading of the thermograms and reducing the surrounding noise.

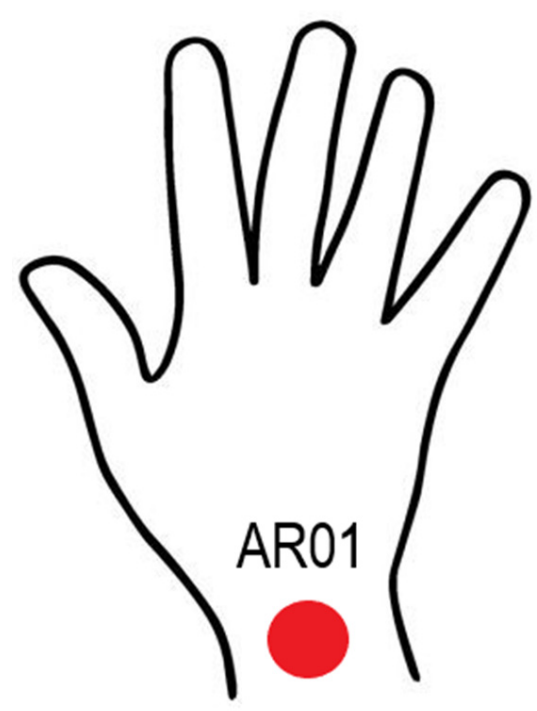

Figure 2. ROI (region of interest) taken for temperature analysis on the palms and back of the hand of the study subjects.

\subsubsection{Handling of the Participants}

Prior to the start of the test, each participant was checked for compliance with the requirements, that is, no caffeine, alcohol, vasodilator drugs, or smoking, to continue with the tests. For this purpose, they were given a reminder the day before the tests were to take 
place. The female menstrual cycle was considered. Nevertheless, none of the participants had their menstrual period during the intakes.

Afterwards, a black board formed of foil wood with plastic laminate was placed on the chair, on which the shots were taken of the palms and backs of the hands. This board had tape markers, which worked as guides to provide precise and reproducible positioning of the hands. Each participant was instructed not to touch the board directly to prevent hand heat from being retained on the board and causing noise on the thermograms. The participant was asked to position him/herself behind the chair and bend down a little until his/her fingers were positioned over the marks. Then, a sequence of infrared images was taken, spaced every 5 min at times 5, 10, 15, and 20 (based on Vardasca, R., E. Francis, J. Ring, P. Plassmann, C.D. Jones, and J. Gabriel [47], and García, A. [48]) for each participant (Figure 3). After each thermal image of the palms and back of the hands was taken, the participant waited seated in another chair, while five minutes remained to continue with the next shot, until the four moments were completed. Thermal imaging sessions were held Monday through Friday from 3:30 to 4:30 pm (hours established by the company), with three participants per day.

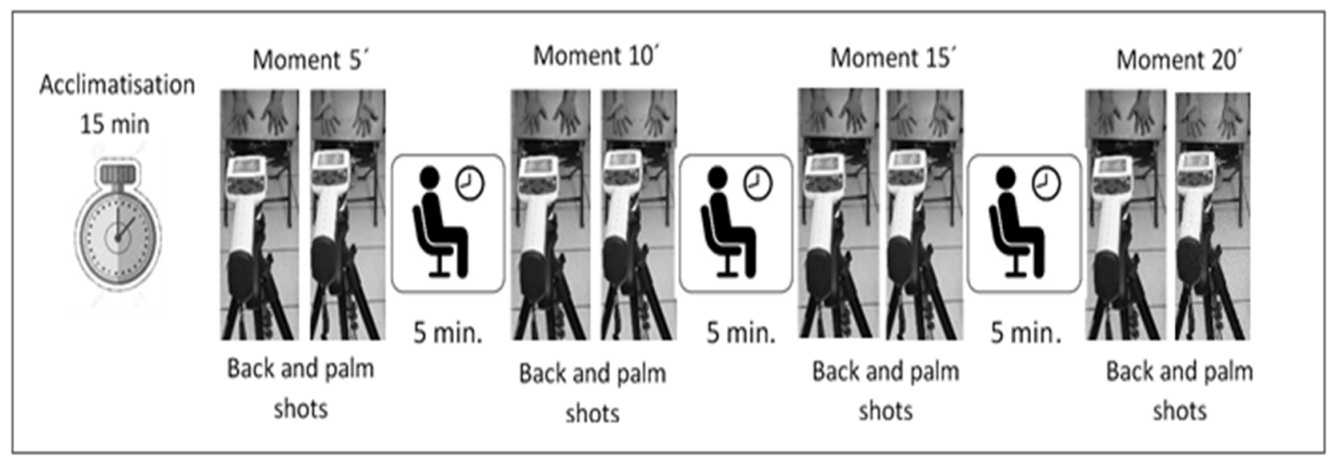

Figure 3. Experimental setup diagram.

The thermal images were then downloaded and analyzed through the ThermaCAM Researcher Pro 2.10 software, from FLIR Systems company, located at Boston, MA, USA, with which a total of 264 images were reviewed. When analyzing each IT image, the color palette was configured in the rain option. The emissivity (0.98) was already adjusted during the shots. The IR image was delimited according to the ROI in order to measure the temperature in that area. Then, the Results option was activated to display the temperature values of maximum, minimum, max-min, average, and standard deviation (Figure 4).

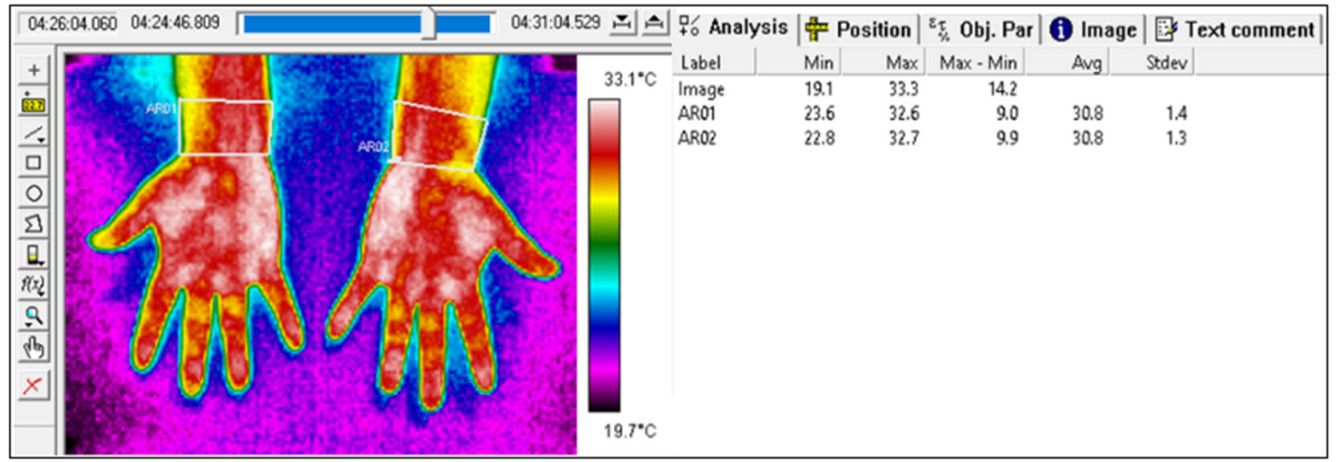

Figure 4. ThermaCAM Researcher Pro 2.10 software display. 
Next, the data were exported to Excel to organize and group according to the times in which the temperatures were recorded $\left(5^{\prime}, 10^{\prime}, 15^{\prime}\right.$, and $\left.20^{\prime}\right)$. Afterwards, the temperature differences were calculated for the minimum and maximum values of the temperature captured by the thermographic camera. Thereafter, the thermal asymmetries that could represent a possible injury were identified and classified in their levels of alarm and severity, as established by Marins et al. [49], and as shown in Table 1.

Table 1. Scale of the level of attention given according to differences of temperatures between the body ROI (body region of interest) against laterals or between two shots of the same ROI.

\begin{tabular}{cc}
\hline Temperature Differences & Level of Attention \\
\hline$\leq 0.4^{\circ} \mathrm{C}$ & Normal \\
$0.5-0.7^{\circ} \mathrm{C}$ & Follow-up \\
$0.8-1^{\circ} \mathrm{C}$ & Prevention \\
$1.1-1.5^{\circ} \mathrm{C}$ & Warning \\
$\geq 1.6^{\circ} \mathrm{C}$ & Seriousness \\
\hline
\end{tabular}

Source: Marins, J. C. B., I. Fernández, J. Arnaiz, A. A. Fernandes and M. Sillero [49].

Subsequently, an OCRA evaluation was performed in the two study areas to compare the results with the proposed model.

\subsubsection{Statistical Analysis}

For the analysis process of the acquired data, the study factors were grouped together. Age was grouped in young age ( $<40$ years of age) and mature age ( $\geq 40$ years old), and for gender, value 1 was assigned to male and 0 to female; BMI was classified as non-obese $\left(<30 \mathrm{~kg} / \mathrm{m}^{2}\right)$ and obese $\left(\geq 30 \mathrm{~kg} / \mathrm{m}^{2}\right)$. BP was classified in normal, high, and low, with normal and high heart rate, and RR in normal and high. Value 1 was assigned to subjects who had an injury or discomfort, and 0 to participants with no injuries.

The statistical analyses were carried out in IBM SPSS Statistics v. $25^{\circledR}$ software, from IBM Corp at Armonk, NY, USA, with which the data normality tests were performed using the Shapiro-Wilk test. Once the normal and non-normal data were identified, nonparametric tests were performed (Mann-Whitney), which were applied to all data due to the small sample size [50]. The relationship of the influence of the factors with the temperature differences was determined. Mixed-design analysis of variance was used to identify significant factors. Regression models and response surfaces were generated by Minitab 17. Three types of regression models were constructed using (a) study factors (age, gender, BMI, BP, RR, and heart rate), (b) relevant risk factors in OCRA (recovery factor, strength factor, posture and movement factor, and frequency factor), and (c) all of the above. The differences obtained with $p<0.05$ were considered statistically significant with a $95 \%$ confidence interval.

The following flow chart summarizes the procedure carried out to obtain thermal images, up to the generation of the prediction models.

\section{Results}

\subsection{Demographic Characteristics of the Participants}

Tables 2 and 3 show the series of data obtained by taking vital signs and somatometry pertaining to each of the participants in the sanding and tolex production areas, respectively.

\subsection{Thermal Imaging}

A total of 264 thermal images from the palmar and dorsal regions of the hand were analyzed, nineteen from the sanding area and fourteen from the tolex area. Figures 5 and 6 show some examples of the images captured from the palmar and dorsal regions of the hand, respectively. The thermograms were from moments $5^{\prime}, 10^{\prime}, 15^{\prime}$, and $20^{\prime}$ after they had performed their tasks for approximately $8.5 \mathrm{~h}$, with two breaks ( $30 \mathrm{~min}$ for the first break and $15 \mathrm{~min}$ for the second). 
Table 2. Demographic characteristics from the sanding area.

\begin{tabular}{cccc}
\hline Attribute & Category & QTY & Percentage \\
\hline Gender & Male & 18 & $95 \%$ \\
& Female & 1 & $5 \%$ \\
Age & Average $=33 \pm 9.7$ years & & \\
RMI & Rank $=18-52$ years & & $74 \%$ \\
& No obese & 14 & $26 \%$ \\
Obese & 5 & \\
& Average $=27 \mathrm{~kg} / \mathrm{m}^{2}$ & & $84 \%$ \\
& Normal & 16 & $5 \%$ \\
Heart rate & Low & 1 & $11 \%$ \\
& High & 2 & $89 \%$ \\
RR & Normal & $17 \%$ \\
& High & 2 & $58 \%$ \\
Injury & Normal & 11 & $42 \%$ \\
Dominant hand & High & 8 & \\
\hline QTY (quantity), BMI (body mass index), BP (blood pressure), RR (respiratory rate).
\end{tabular}

Table 3. Demographic characteristics from the tolex area.

\begin{tabular}{cccc}
\hline Attribute & Category & QTY & Percentage \\
\hline Gender & Male & 8 & $57 \%$ \\
& Female & 6 & $43 \%$ \\
Age & Average $=35 \pm 7.45$ years & & \\
BMI & Rank $=26-48$ years & & \\
& No obese & 9 & $36 \%$ \\
& Obese & 5 & $79 \%$ \\
BP & Average $=28.4$ kg $/ \mathrm{m}^{2}$ & & $7 \%$ \\
& Normal & 11 & $14 \%$ \\
Heart rate & Low & 1 & $71 \%$ \\
& High & 2 & $29 \%$ \\
RR & Normal & 10 & $71 \%$ \\
& High & 4 & $29 \%$ \\
Injury & Normal & 10 & \\
Dominant hand & High & 4 & \\
\hline
\end{tabular}

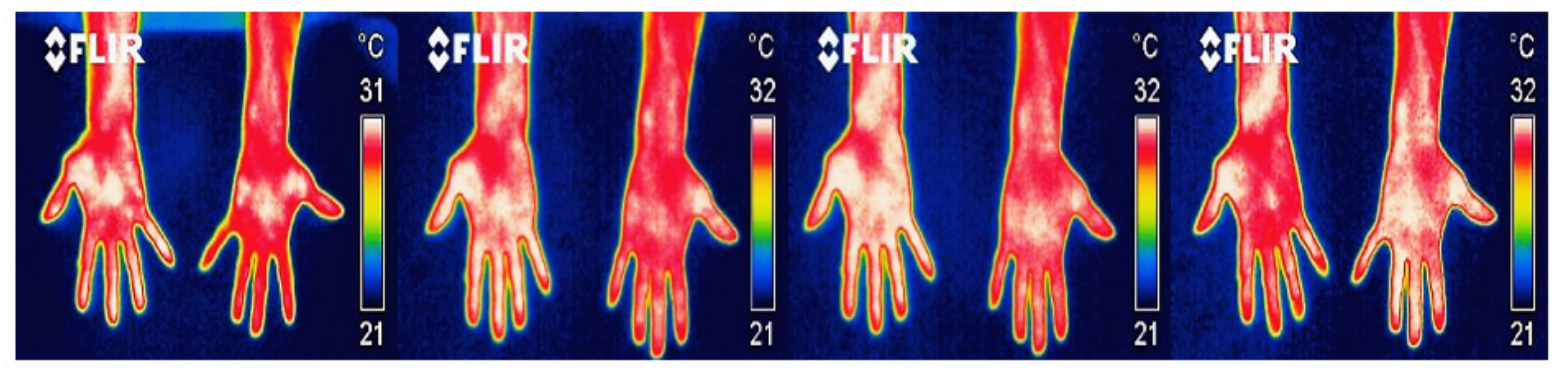

Figure 5. Example of thermogram taken from the front area of the palm at the times $5^{\prime}, 10^{\prime}, 15^{\prime}$, and $20^{\prime}$.

The first thermogram was taken after $5 \mathrm{~min}$ of rest, and after the participant's highly repetitive activity (in this case, sanding). The sequence of thermograms corresponds to a single participant. This volunteer presented the maximum asymmetry. In the images of Figures 5 and 6, in particular, the fingers and wrist of the right hand show the highest temperature values compared to the left hand. However, this volunteer did not report having any injury or discomfort in his hands. 


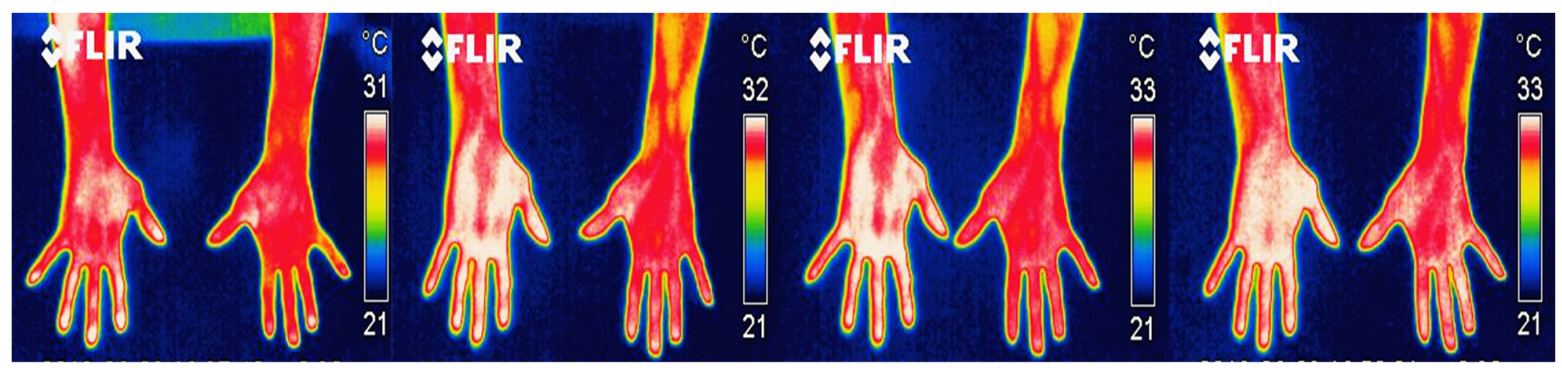

Figure 6. Thermogram from the back of the hand of one of the participants at moments $5^{\prime}, 10^{\prime}, 15^{\prime}$, and $20^{\prime}$.

Table 4 shows the minimum and maximum temperature differences of the palmar and dorsal areas between the right and left wrists calculated for each period.

Table 4. Values of the minimum and maximum temperature differences from the back of the hand obtained from the participants by time.

\begin{tabular}{ccccccccc}
\hline Participant & $\Delta$ T5 Min & $\Delta$ T5 Max & $\Delta$ T10 Min & $\Delta$ T10 Max & $\Delta$ T15 Min & $\Delta$ T15 Max & $\Delta$ T20 Min & $\Delta$ T20 Max \\
\hline Subject 1 with an injury & 0.3 & 0.4 & 2.1 & 0.4 & 0.2 & 0.7 & 0.3 & 0.7 \\
Subject 2 with an injury & 0.5 & 0.3 & 1.6 & 0.2 & 0.2 & 0.4 & 0.1 & 0 \\
Healthy Subject 1 & 0.4 & 0 & 0.6 & 0.4 & 0.8 & 0.4 & 1.6 & 0.2 \\
Healthy Subject 2 & 3.4 & 0.6 & 1 & 0.5 & 2.9 & 0.1 & 2.3 & 0.2 \\
Healthy Subject 3 & 0 & 0.4 & 0.4 & 0.1 & 0.5 & 0.2 & 0.2 & 0.1 \\
\hline
\end{tabular}

$\Delta \mathrm{T}=$ The temperature (minimum or maximum) of the back of the right hand and the temperature (minimum or maximum) of the back of the left hand.

By analyzing the behavior of the minimum and maximum temperature differences of the participants' wrists from their palmar and dorsal hand areas over time $\left(5^{\prime}, 10^{\prime}\right.$, $15^{\prime}$, and $20^{\prime}$ ), the palmar zone showed higher temperature values than the dorsal region in the minimum temperature differences. This is true for both study areas, as shown in Figures 7 and 8. In other research carried out by García, A., C. Camargo, J. Olguín, and J.A.L. Barreras [51], highly repetitive activities were analyzed by means of sensory thermography, in which wrist temperatures were evaluated, and, in all cases, temperature increases of more than $0.6{ }^{\circ} \mathrm{C}$ in $15 \mathrm{~min}$ were identified. In the same context, in the research of Camargo, C., J. Ordorica, E.J. De la Vega, J.E. Olguín, O.R. López, and J.A. López [52], where temperature changes in the wrists were measured by sensory thermography, when performing highly repetitive movements, the maximum temperatures of $35.078^{\circ} \mathrm{C}$ in the right wrist and $34.663^{\circ} \mathrm{C}$ in the left wrist were obtained.

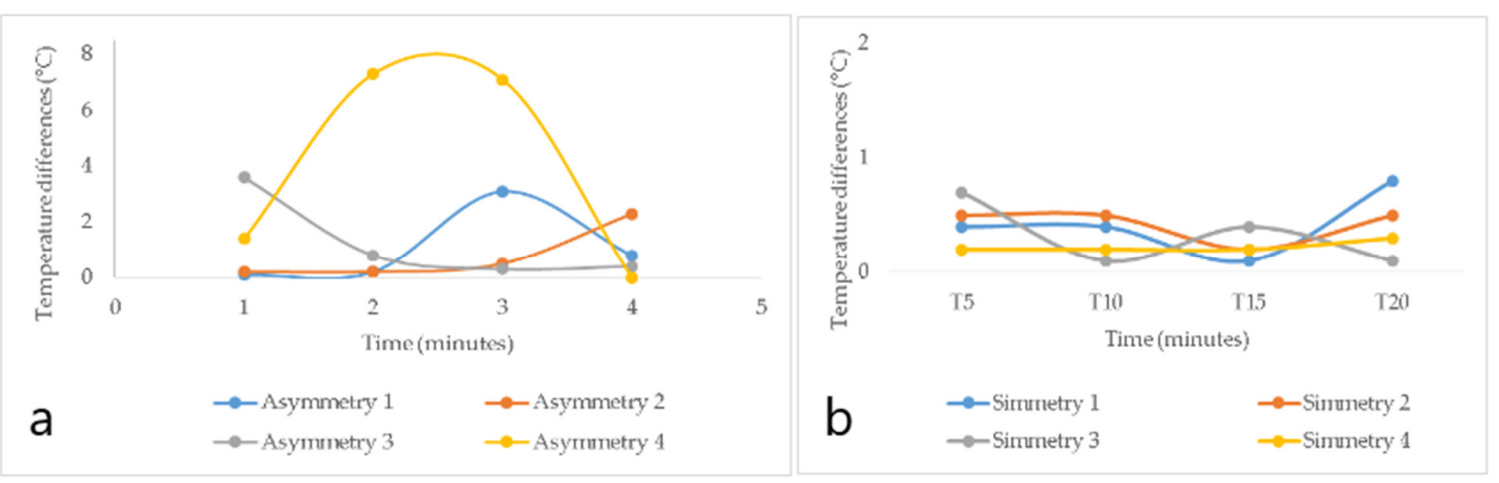

Figure 7. Behavioral graph of minimum temperature differences for the palm of the hand in the subjects of the sanding area. (a) corresponds to subjects with asymmetries. (b) represents subjects with symmetries. 


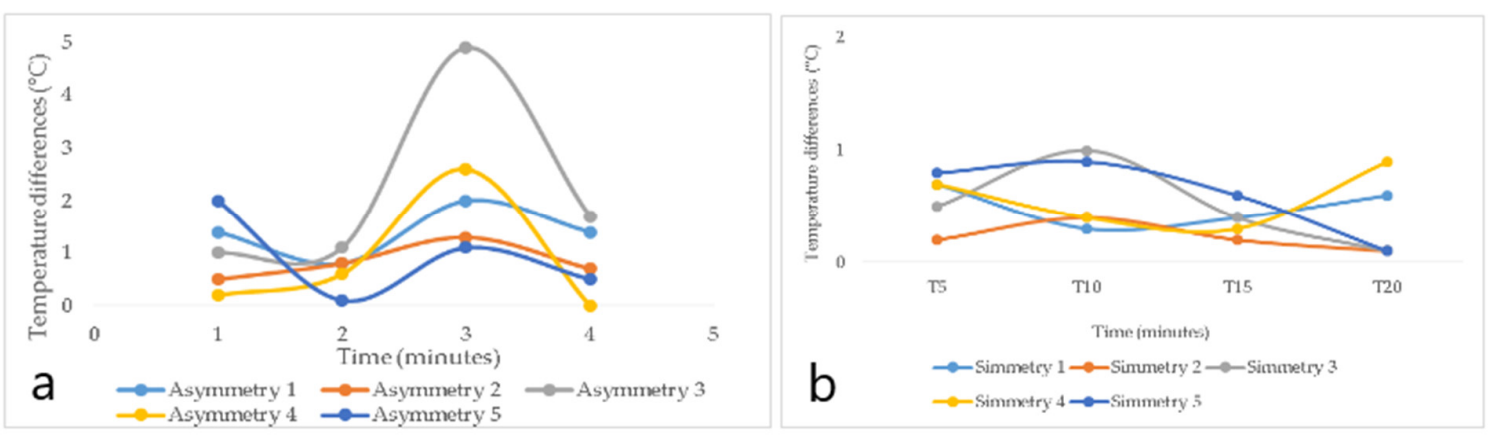

Figure 8. Graph of behavior of minimum temperature differences of the palm of the hand from the tolex area. (a) corresponds to subjects with asymmetries. (b) represents subjects with symmetries.

Figure 7 shows the temperature difference behavior of the participants from the sanding area, and it was observed that four subjects had asymmetries $\left(\geq 1.1^{\circ} \mathrm{C}\right)$ on Figure $7 \mathrm{a}$, representing the possibility of suffering from a CTD. Moreover, hands with asymmetry showed a great deal of temperature variations over time, while hands with symmetry (healthy hands) produced minimal temperature variations (Figure $7 \mathrm{~b}$ ).

Figure 8 shows the temperature difference behavior of the participants from the tolex area, and it was observed that five participants had asymmetries $\left(\geq 1.1^{\circ} \mathrm{C}\right)$, representing the possibility of suffering from a CTD. Subjects with asymmetry showed a great deal of temperature variations over time (Figure 8a), with a tendency to decrease slightly in time $10^{\prime}$, then increase in time $15^{\prime}$, and finally decrease in time $20^{\prime}$. Healthy subjects, on the other hand, had minimal variations over time (Figure $8 b$ ).

The minT R point represents the minimum temperature of the right wrist (palm side), and the minT L point corresponds to the minimum temperature of the left wrist (palm side). In Figure 9, there were fifteen cases with temperature difference between the minT $\mathrm{R}$ and $\operatorname{minT} \mathrm{L}$ points representing thermal asymmetries $\left(\geq 1.1^{\circ} \mathrm{C}\right)$ with subjects probably suffering from a CTD.

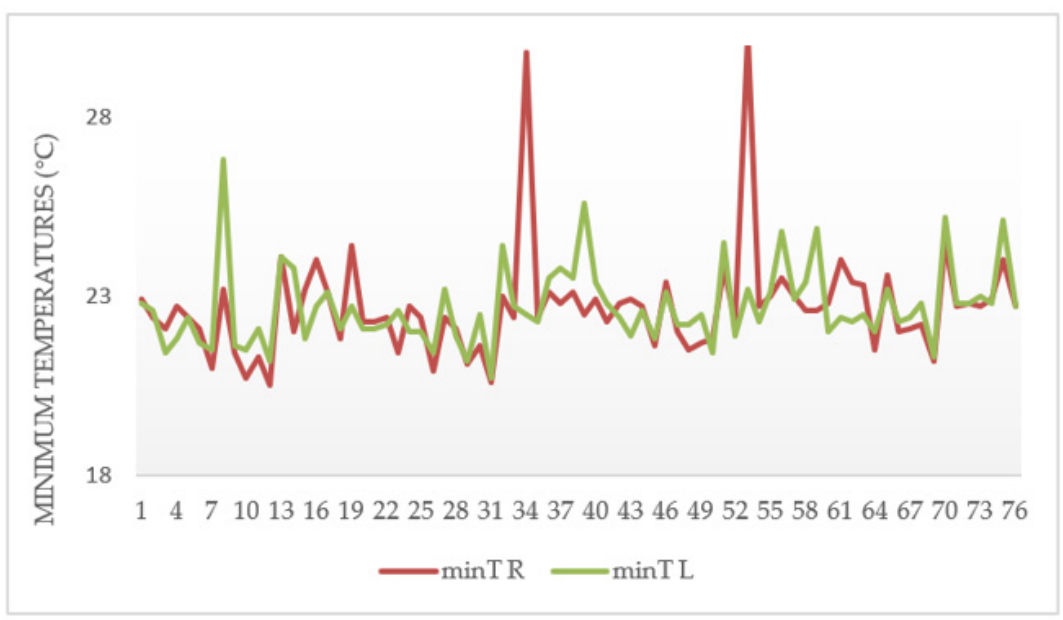

Figure 9. Graphs of minimum temperature differences between minT R (right wrist minimum temperature) and minT L (left wrist minimum temperature) points of subjects from the sanding area.

The minT R point represents the minimum temperature of the right wrist (palm side), and the minT L point corresponds to the minimum temperature of the left wrist (palm side). Ten cases of thermal asymmetries were observed in the graph of Figure 10, which represents subjects probably suffering from a CTD. 


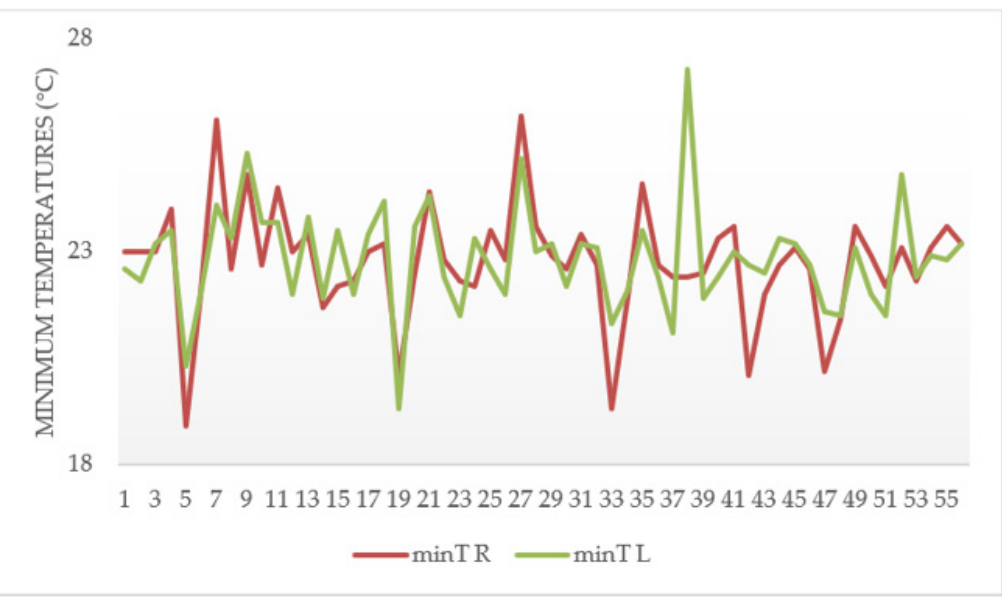

Figure 10. Graphs of minimum temperature differences between minT R (right wrist minimum temperature) and minT L (left wrist minimum temperature) points of subjects from the tolex area.

Regarding the diagnoses of injuries by means of an IT, Table 5 provides a summary of the participants who reported having symptoms with suspected CTD, or with a confirmed diagnosis of tendinitis, as well as the asymmetries obtained and their levels of attention and the diagnoses obtained by thermal imaging. It is worth pointing out that seven out of nine subjects were successfully classified. Table 6 shows the results of the OCRA evaluation to measure the risk of highly repetitive activities carried out in the study areas, where all of the participants are identified as having an unacceptably high risk, which coincides with the injury conditions of the participants shown.

Table 5. Diagnostic results of asymmetric wrist injuries in the palmar region of the hand.

\begin{tabular}{ccccc}
\hline Subject with Injuries & Area & Maximum Asymmetry $\left({ }^{\circ} \mathbf{C}\right.$ ) & Level of Attention & $\begin{array}{c}\text { Injury Diagnosis } \\
\text { (Warning/Seriousness) }\end{array}$ \\
\hline 1 & Sanding & 3.1 & Serious & Yes \\
2 & Sanding & 2.3 & Serious & Yes \\
3 & Sanding & 2.1 & Serious & Yes \\
4 & Sanding & 0.9 & Prevention & No \\
5 & Sanding & 1.8 & Serious & Yes \\
6 & Sanding & 2 & Serious & No \\
7 & Sanding & 0.4 & Normal & Yes \\
8 & Sanding & 1.7 & Serious & Yes \\
9 & Tolex & 4.9 & Serious & \\
\hline
\end{tabular}

Table 6. Results of the OCRA assessment conducted in the study areas.

\begin{tabular}{|c|c|c|c|c|c|}
\hline Subject with Injuries & Area & OCRA Checklist Index & Risk Level & Recommended Action & Equivalent OCRA Index \\
\hline 1 & Sanding & 63 & unacceptable high risk & $\begin{array}{l}\text { Job upgrading, medical } \\
\text { supervision, and training }\end{array}$ & $>9$ \\
\hline 2 & Sanding & 63 & unacceptable high risk & $\begin{array}{l}\text { Job upgrading, medical } \\
\text { supervision, and training }\end{array}$ & $>9$ \\
\hline 3 & Sanding & 63 & unacceptable high risk & $\begin{array}{l}\text { Job upgrading, medical } \\
\text { supervision, and training }\end{array}$ & $>9$ \\
\hline 4 & Sanding & 63 & unacceptable high risk & $\begin{array}{l}\text { Job upgrading, medical } \\
\text { supervision, and training }\end{array}$ & $>9$ \\
\hline 5 & Sanding & 63 & unacceptable high risk & $\begin{array}{l}\text { Job upgrading, medical } \\
\text { supervision, and training }\end{array}$ & $>9$ \\
\hline 6 & Sanding & 63 & unacceptable high risk & $\begin{array}{l}\text { Job upgrading, medical } \\
\text { supervision, and training }\end{array}$ & $>9$ \\
\hline 7 & Sanding & 63 & unacceptable high risk & $\begin{array}{l}\text { Job upgrading, medical } \\
\text { supervision, and training }\end{array}$ & $>9$ \\
\hline 8 & Sanding & 63 & unacceptable high risk & $\begin{array}{l}\text { Job upgrading, medical } \\
\text { supervision, and training }\end{array}$ & $>9$ \\
\hline 9 & Tolex & 51.8 & unacceptable high risk & $\begin{array}{l}\text { Job upgrading, medical } \\
\text { supervision, and training }\end{array}$ & $>9$ \\
\hline
\end{tabular}


According to the response surfaces generated, corresponding to Figures 11 and 12, it was determined that the maximum values for temperature differences had normal levels in $\mathrm{BP}$ and heart rate.

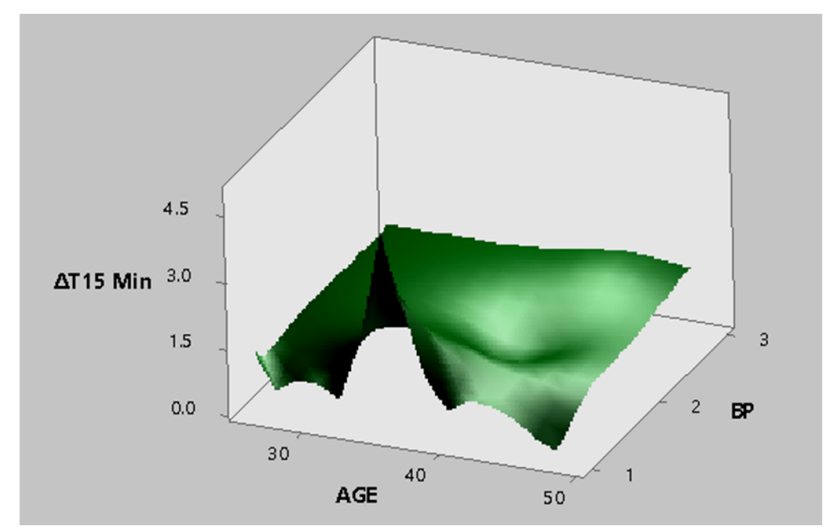

Figure 11. Response surface produced for the tolex area from the palm of the hand for the minimum temperature difference in time $15^{\prime}$ and the factors age and BP.

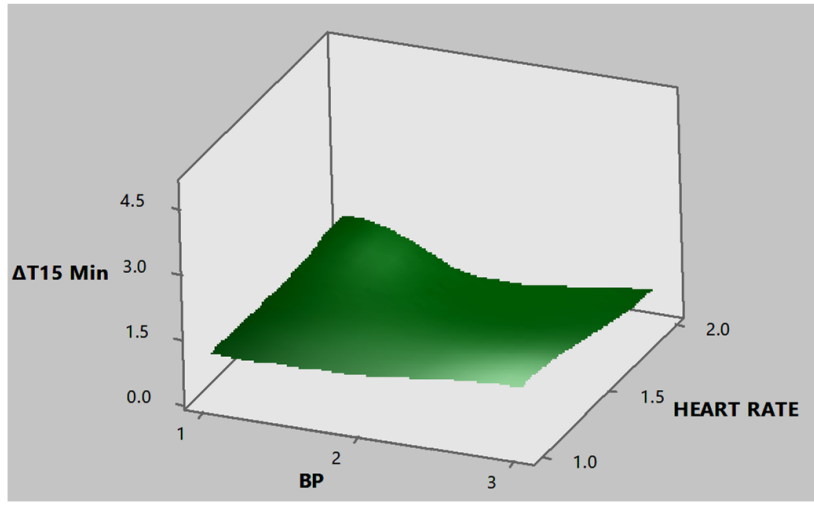

Figure 12. Response surface produced for the tolex area from the palm of the hand for the minimum temperature difference in time $15^{\prime}$ and the $\mathrm{BP}$ and heart rate factors.

The data normality test using Shapiro-Wilk yielded both normal and non-normal data. Since the two samples were small in size, the Mann-Whitney U test was performed for all data [50]. Table 7 shows a summary where the factors BP $(p=0.036, p=0.014)$, heart rate $(p=0.047, p=0.023), \operatorname{RR}(p=0.020, p=0.036)$, and age $(p=0.010)$ were determined to be statistically significant for temperature differences, according to the non-parametric tests performed. The sanding area reported the factors BP, heart rate, and RR to be very significant, that is, associated with CTD, while in the tolex area, only the RR and age factors were determined as significantly linked with CTD. The sanding area showed higher significant values than the tolex area, predominating the time $10^{\prime}$ and the minimum temperature differences.

The mixed-design ANOVA results (see Table 8 ) confirmed a relationship between the factor BP $(p=0.009)$ and heart rate $(p=0.040)$ in the back, and BP $(p=0.009)$ and heart rate $(p=0.002)$ in the palm as significant regarding temperature difference in the sanding area. None of the factors evaluated were significant for the tolex area. Table 9 briefly shows the quadratic regression models generated according to the factors used. Firstly, the results of the study factors (age, gender, BMI, BP, RR, and heart rate) are displayed, with the determination coefficients, the estimates of which were adjusted appropriately to the study variable. Then, the values of the coefficients corresponding to the factors of the OCRA method are shown (recovery factor, strength factor, posture and movement factor, and frequency factor), and finally, we used all of the factors mentioned. 
Table 7. Mann-Whitney U-test of study factors for temperature differences.

\begin{tabular}{ccccc}
\hline Area-Section & Factor & Time (Min) & Temperature Differences & $p$-Value \\
\hline Sanding-Back & BP & 10 & Maximum & 0.036 \\
Sanding-Back & BP & 15 & Minimum & 0.014 \\
Sanding-Palm & BP & 10 & Minimum & 0.014 \\
Sanding-Palm & Heart rate & 10 & Minimum & 0.047 \\
Sanding-Palm & Heart rate & 15 & Minimum & 0.023 \\
Sanding-Palm & RR & 20 & Minimum & 0.02 \\
Tolex-Back & RR & 15 & Maximum & 0.036 \\
Tolex-Back & Age & 10 & Minimum & 0.01 \\
\hline
\end{tabular}

Table 8. Mixed-design analysis of variance of the study factors for the sanding area.

\begin{tabular}{ccc}
\hline Area-Section & Factor & $p$-Value \\
\hline Sanding-Back & BP & 0.009 \\
Sanding-Back & Heart rate & 0.040 \\
Sanding-Palm & BP & 0.009 \\
Sanding-Palm & Heart rate & 0.002 \\
\hline
\end{tabular}

Table 9. Summary of models by zone, hand section, and factors included.

\begin{tabular}{ccccc}
\hline Area & Hand Section & Model (Factors Included) & R-sq & R-sq (Adj) \\
\hline Sanding & Back & Proposed factors & 0.8836 & 0.7905 \\
Sanding & Palm & Proposed factors & 0.9737 & 0.9475 \\
Tolex & Palm & Proposed factors & 0.9667 & 0.9134 \\
Sanding & Back & OCRA factors & 0.2583 & 0.0993 \\
Sanding & Palm & OCRA factors & 0.5854 & 0.4965 \\
Tolex & Back & OCRA factors & 0.3455 & 0.1492 \\
Tolex & Palm & OCRA factors & 0.3481 & 0.1525 \\
Sanding & Back & All factors & 0.9078 & 0.6864 \\
Sanding & Palm & All factors & 0.9850 & 0.9488 \\
Tolex & Back & All factors & 0.9697 & 0.8031 \\
Tolex & Palm & All factors & 0.9871 & 0.9164 \\
\hline
\end{tabular}

$\mathrm{R}$-sq (coefficient of determination). R-sq (Adj) (Adjusted coefficient of determination).

The highest values for temperature differences are observed in a middle age range (36 years) and with a normal level in BP.

\section{Discussions}

In this study, $75 \%$ of the cases that indicated injury or discomfort were detected by IT in the sanding area, while in the tolex area, just one case was reported. In addition, Papež et al. [53] and Papež, B., Jesenšek, M. Palfy, M. Mertik and Z. Turk [54] established that IT allows the correct classification of $72.2 \%$ of the hands, healthy and pathological, based on the dorsal part of the hand, while when seriously affected hands and healthy hands are evaluated, the percentage rises to $>80 \%$. Palfy and Papez [55] used 44 thermograms of healthy and pathological hands to determine the effectiveness of IT as a diagnostic method for CTS. Using IT and intelligence systems, they were able to diagnose cases of CTS with a success rate close to or above $80 \%$.

Tkáčová et al. [20] recorded 14 thermal images to determine the level of effectiveness of IT for diagnosing CTS. The success rates found in the classification of healthy and pathological hands for were close to $80 \%$. In the same context, Tchou et al. [56] recorded 122 thermograms, and obtained success rates for the classification of healthy hands with CTS pathologies close to or higher than $80 \%$.

Therefore, IT has been shown to be remarkably effective in detecting asymmetries, which are known to be disease indicators, particularly CTS. However, our research detected asymmetries in the dorsal and palmar surfaces of the hand, contrary to other studies $[20,21,53-56]$, 
who concluded that the dorsal side of the hand provides more satisfactory results when diagnosing CTS than the palmar area of the hand.

Ninety percent of the participants from the sanding area exhibited asymmetries with alert or serious attention. Out of the 17 subjects with asymmetries, $76 \%$ exhibited levels outside the normal range in at least one of the study factors (age, BMI, BP, heart rate, or RR), while $79 \%$ of the participants from the tolex area exhibited asymmetries with alert or serious levels. Out of the 11 subjects with asymmetries, $73 \%$ had levels outside the normal range in at least one of the study factors.

As for the sanding area, $94 \%$ of the participants with asymmetries are men (with less than one year working in the area), and the other $6 \%$ is the only female operator in the area. Regarding the tolex area, $36 \%$ of the participants with asymmetries are women, while $64 \%$ are men (the subjects have been working in the area for two to eight years.) It should be inferred that the sanding area would have a higher percentage of injuries, due to the fact that the production activities that are carried out demand more movement for the wrists than for the tolex area.

Moreover, other hypotheses are based on the production rate that has been increasing by $50 \%$, leading to faster movements in the wrists, thus hurting them. Given that seven out of eight people with injuries from the sanding area have been working there for such a short time (less than a year), this is alarming. In fact, one operator who had been working in the area for only six months was disabled due to tendinitis during the study; this was contrary for the participants from the tolex area who have been working there for two to eight years. Another participant was also diagnosed with tendinitis, although it was not detected by IT.

By analyzing the behavior of the minimum and maximum temperature differences by time, the highest value of $6.5^{\circ} \mathrm{C}$ (temperature difference between the back of the right and left hand) was identified for the sanding area in the minimum temperature values, in a time of $15 \mathrm{~min}$ for the back of the hand section. For the tolex area, the minimum temperature differences with the highest value on the back of the hand were shown in time $10^{\prime}\left(2.6^{\circ} \mathrm{C}\right)$. For the maximum temperature differences, the highest value $\left(1.6^{\circ} \mathrm{C}\right)$ was recorded at time $15^{\prime}$. In the palms section, its maximum value in the sanding area was $7.3^{\circ} \mathrm{C}$ for the minimum temperature difference between the right and left palm, recorded in time $10^{\prime}$. In the case of the tolex area, for the palmar region of the hand, the highest value was in time $15^{\prime}$ with $5^{\circ} \mathrm{C}$ for the minimum temperature difference. On the other hand, for the maximum temperature difference, its highest value was $1.1^{\circ} \mathrm{C}$ in time $20^{\prime}$.

The factors age, BMI, heart rate, and RR have data with a normal distribution, whereas the factors gender, dominant hand, and BP exhibited abnormal distribution for the sanding area. In the tolex area, normality tests identified age and BMI as data with normal distribution, and the factors gender, BP, injury, heart rate, and RR exhibited abnormal distribution.

When carrying out the non-parametric tests for the back of the hand, the influence of the $\mathrm{BP}$ on the maximum temperature difference in time $10^{\prime}$ for the sanding area was verified. The relationship between the minimum temperature differences and $\mathrm{BP}$ for the palmar section of the hand was identified in time 10; heart rate in times $10^{\prime}$ and $15^{\prime}$; and finally, RR in the minimum temperature difference in time $20^{\prime}$. An influence relationship between RR and the maximum temperature differences for the section of the back of the hand was found in time $15^{\prime}$. As for the tolex area, an influence relationship between RR and the maximum temperature differences for the back section of the hand was found in time $15^{\prime}$. There was no influence relationship for the palmar region of the hand.

The factors that influence the minimum temperature differences on the back of the hand for the sanding area are $\mathrm{BP}$ in time $15^{\prime}$, heart rate in times $10^{\prime}$ and $15^{\prime}$, and RR in time $20^{\prime}$. A relationship with $\mathrm{BP}$ in time $10^{\prime}$ was identified for the maximum temperature differences.

Regarding the non-parametric tests in the tolex area, in the section of the back of the hand, an influence relationship was found between RR and the maximum temperature differences in time $15^{\prime}$. In the palmar section of the hand, an influence was identified between age and the minimum temperature differences in time $10^{\prime}$. Concerning the factors 
that influence the minimum temperature differences in the palm of the hand for the sanding area, these are BP in time $10^{\prime}$, heart rate in times $10^{\prime}$ and $15^{\prime}$, and RR in time $20^{\prime}$.

The results indicate that the interaction between the significant factors for the sanding area and the main asymmetries had a low BP. On the other hand, in the tolex area, $80 \%$ of the asymmetries had normal BP. With regard to heart rate, for the palm of the hand in the sanding area, one out of three asymmetries were observed with a high heart rate (the highest value) for time $10^{\prime}$, while in time $15^{\prime}$, two out of three asymmetries exhibited a high heart rate. In the tolex area, $80 \%$ of the asymmetries included normal heart rhythms. For the RR, both areas were found to have normal RR for the diagnosed asymmetries. Regarding age, in the tolex area, $100 \%$ were young, both for time $10^{\prime}$. In contrast, other research $[23,30,32,35]$ established that CTS increases with age, while several studies establish that age is associated with the prevalence of CTS $[22,31,33,57]$.

In the area of sanding, it was not possible to evaluate the gender factor, since there is only one woman in this section. However, various studies [22,24,29,30,35] found an association between CTS and the female gender. However, there is also research that found no relationship between gender and CTS [27]. In the present study, BMI was not determined to be a significant risk factor, whereas other studies have found a strong association with CTS $[22,30,33,35,57-61]$.

When carrying out the mixed-design analysis of variance for the sanding area, BP and heart rate turned out to be significant factors for the back and palm. Based on the mixed-design analysis of variance, for the tolex area, factors were determined to be nonsignificant. The regression models developed with the study factors obtained a coefficient of determination of 0.9737 for the sanding palm area, and a coefficient of determination of 0.9667 for the tolex palm area. It is worth mentioning that, to attain these percentages, all of the study factors are included in the equations, since omitting them would considerably reduce the determination coefficients.

On the other hand, the models constructed using the OCRA method generated lower coefficients of determination. For sanding palm, $R^{2}=0.5854$ and for tolex palm, $R^{2}=0.3481$. However, when both groups of factors were integrated into a single regression model, the best results were obtained with the following coefficients of determination: 0.9850 for sanding palm and 0.9871 for tolex palm. Meanwhile, research conducted by Márquez Gómez, M. [41] achieved an accuracy of $83.91 \%$ and a kappa index of $63.14 \%$ in their statistical model for the prediction of WRMSD-related (work-related musculoskeletal disorders) discomfort in the hands/wrists, in which they considered six factors: postural overload, repetitiveness of movements, gender, medical history related to MSD, frequency of household chores, and job rotation. In another study, multiple regression models were developed to predict the combined frequency and severity of the pain from WRMSDs, achieving an R-squared of 32.9\% [62]. In addition, Sasikumar, V. and S. Binoosh [63] employed various machine learning algorithms in their predictive model for WRMSDs among computer professionals, considering postural, physiological, and work-related factors, with an accuracy of $81.25 \%$.

\section{Limitations}

During the process of obtaining data in a maquiladora* company and acquiring the thermograms, the humidity levels ( $45 \%$ to $60 \%$ ) depended greatly on the climatic conditions. For the application of questionnaires and the taking of vital signs and somatometry, as well as the taking of thermal images, there was a restricted schedule in order not to affect the daily production goals for the company.

\section{Conclusions}

This research proved the effectiveness of IT in the detection of suspected CTS injuries by means of thermal asymmetries in the wrists. Three temperature prediction models were developed based on the study factors, two for the sanding area, with which it is possible to make predictions of the temperature differences for times of 10 and 15 min to determine 
whether or not the subject exhibits thermal asymmetries that could lead to injury, and another for the tolex area, with predictions for times of $15 \mathrm{~min}$. The maximum thermal asymmetries were registered for the minimum temperature differences, both in the sections of the back of the hand and in the palm of the hand in both study areas.

Ninety-four percent of the participants in the sanding area had thermal asymmetries with a degree of alert or seriousness attention, while for the tolex area, only 73 percent had them. In the tolex area, 36\% of the participants with thermal asymmetries with a degree of alert or seriousness attention are women, while $64 \%$ are men. The subjects have been working in this area from two to eight years. In the area of sanding, $94 \%$ of the participants with asymmetries (alert or seriousness level) are men, and have been working in the area for less than one year.

Factors such as age, BP, heart rate, and RR were found to highly influence injuries in participants. However, no strong association with BMI was found. It is inferred that participants who exhibit levels out of the normal range for at least one of the factors, such as advanced age ( $\geq 40$ years), BMI, BP, heart rate, or RR, are highly likely to have wrist injuries with a level of attention that is alarming or serious, so it is important to follow up with staff who exhibit such characteristics and consider these results during the recruitment process. In this study, in sanding area, the RR factor stands out, with a high level in personnel with thermal asymmetries of alert or seriousness, while for the tolex area, advanced age predominates.

Finally, these are preliminary results from a limited number of thermal images, so in the next section proposals are made that include increasing the sample size.

\section{Future Research}

To continue with the development of this research, it is proposed to carry out future studies of wrist temperature, comparing temperatures before starting activities with the peak time of work activity. This will allow for a more accurate assessment of temperature differences compared to time. It is suggested to analyze the values of average temperatures, as well as the study of other ROIs in the hands. In addition, it is recommended to carry out studies of temperature differences considering a large sample size, where there is a greater number of participants of both genders, and, if possible, with dominant hand variation. Only nine subjects with injuries were reported, and in one of the study areas, only one person had a left dominant hand, while there were none in the other. For this reason, it is advisable to extend the investigations to other production areas of the same company. In turn, it is advisable to analyze other factors particular to each process, such as force, vibrations, movement amplitude, postural overload, length of employment, overtime, and rotation, or, in the case of tolex, carry out studies on the cold factor, since this area works with low temperatures. Furthermore, it is proposed to apply the standardized Cornell Musculoskeletal Discomfort Questionnaire (CMDQ), used by Acquah et al. [64] in their study of the prevalence and intensity of symptoms of musculoskeletal disorders (MSDs) in workers of informal recycling of electrical and electronic waste. In addition, it is suggested to consider demographic factors, such as smoking, MSD-related medical history, exercise, household chores (studied by Márquez Gómez, M. [41]), physiological factors, work-related factors [63], job fatigue, and strain [65]. Furthermore, we recommend future research on the development of regression models with acceptable determination coefficients, in which only the found influence factors are included. At the same time, we propose to use the machine learning method for the development of predictive models and to make comparisons between both results. Finally, it is suggested to extend the study to other upper extremities, lower extremities, and the lower and upper back to analyze the behavior of temperature differences and to make comparisons between these. 
Author Contributions: Conceptualization, M.A.C.-M.; Investigation, M.A.C.-M., C.C.-W., and R.V.; Data organization, M.A.C.-M. and R.V.; Writing, original draft, M.A.C.-M. and C.C.-W.; Writing, review \& editing, J.L.G.-A.; Supervision, J.A.L.-B. and J.E.O.-T.; Project administration, B.R.G.R.; Funding acquisition, J.E.O.-T. All authors have read and agreed to the published version of the manuscript.

Funding: This research received no external funding.

Institutional Review Board Statement: The study was conducted according to the guidelines of the Declaration of Helsinki, and approved by the Institutional Ethics and Bioethics Committee of Autonomous University of Baja California Campus Ensenada according to protocol code 2020-023 and approved on 20 March 2020.

Informed Consent Statement: Informed consent was obtained from all subjects involved in the study.

Data Availability Statement: Written informed consent has been obtained from the participant(s) to publish this paper.

Acknowledgments: The authors appreciate the doctoral scholarship granted to Melissa Cazares from the Mexican National Council for Science and Technology (CONACYT).

Conflicts of Interest: The authors state that they have no conflicts of interest to declare.

\section{References}

1. Fonseca, M.; Moraga, A. Desórdenes del sistema musculoesquelético por trauma acumulativo en estudiantes universitarios de computación e informática. Cienc. Tecnol. 2010, 26, 1-18.

2. Márquez, M. Theoretical models of musculoskeletal disorders causation. Ing. Ind. Actual. Nuevas Tend. $2015,4,85-102$.

3. Segning, C.; Ezzaidi, H.; da Silva, R.; Ngomo, S. A Neurophysiological Pattern as a Precursor of Work-Related Musculoskeletal Disorders Using EEG Combined with EMG. Int. J. Environ. Res. Public Health 2021, 18, 2001. [CrossRef]

4. Soares, A.L.; Xavier, A.A.D.P.; Michaloski, A.O. Occupational Risk Evaluation through Infrared Thermography: Development and Proposal of a Rapid Screening Tool for Risk Assessment Arising from Repetitive Actions of the Upper Limbs. Int. J. Environ. Res. Public Health 2020, 17, 3390. [CrossRef]

5. Tröster, M.; Wagner, D.; Müller-Graf, F.; Maufroy, C.; Schneider, U.; Bauernhansl, T. Biomechanical Model-Based Development of an Active Occupational Upper-Limb Exoskeleton to Support Healthcare Workers in the Surgery Waiting Room. Int. J. Environ. Res. Public Health 2020, 17, 5140. [CrossRef] [PubMed]

6. Xu, Y.; Song, Y.; Sun, D.; Fekete, G.; Gu, Y. Effect of Multi-Modal Therapies for Kinesiophobia Caused by Musculoskeletal Disorders: A Systematic Review and Meta-Analysis. Int. J. Environ. Res. Public Health 2020, 17, 9439. [CrossRef] [PubMed]

7. Chattopadhyay, R.; Sun, Q.; Fan, W.; Davidson, I.; Panchanathan, S.; Ye, J. Multisource domain adaptation and its application to early detection of fatigue. ACM Trans. Knowl. Discov. Data 2012, 6, 1-26. [CrossRef]

8. Iqbal, Z.A.; Alghadir, A.H. Cumulative trauma disorders: A review. J. Back Musculoskelet. Rehabil. 2017, 30, 663-666. [CrossRef]

9. Ordoñez, C.; Gómez, E.; Calvo, A. Desórdenes músculo esqueléticos relacionados con el trabajo. Rev. Colomb. Salud Ocup. 2016, 6, 24-30. [CrossRef]

10. Baic, A.; Kasprzyk, T.; Rżany, M.; Stanek, A.; Sieroń, K.; Suszyński, K.; Marcol, W.; Cholewka, A. Can we use thermal imaging to evaluate the effects of carpal tunnel syndrome surgical decompression? Medicine 2017, 96, e7982. [CrossRef]

11. Boerner, E.; Bauer, J.; Kuczkowska, M.; Podbielska, H.; Ratajczak, B. Comparison of the skin surface temperature on the front of thigh after application of combined red-IR radiation and diadynamic currents executed in a different sequence. J. Therm. Anal. Calorim. 2015, 120, 921-928. [CrossRef]

12. Boerner, E.; Bauer, J.; Ratajczyk, B.; Dereń, E.; Podbielska, H. Application of thermovision for analysis of superficial temperature distribution changes after physiotherapy. J. Therm. Anal. Calorim. 2015, 120, 261-267. [CrossRef]

13. Cholewka, A.; Drzazga, Z.; Sieron, A.; Stanek, A. Thermovision diagnostics in chosen spine diseasses treated by whole body cryotherapy. J. Therm. Anal. Calorim. 2010, 102, 113-119. [CrossRef]

14. Cholewka, A.; Drzazga, Z.; Sieron, A.; Stanek, A.; Knefel, G.; Kawecki, M.; Nowak, M. Some applications of thermal imaging in medicine in some aspects of medical physics in vivo in vitro studies. Pol. J. Environ. Stud. 2010, 1, 51-58.

15. Cholewka, A.; Knefel, G.; Stanek, A.; Kawecki, M.; Nowak, M.; Sieroń, A.; Drzazga, Z. Thermal imaging and tc oximetry measurements of hyperbaric oxygen therapy (hbo) effects in trophic ulceration of the crura. J. Therm. Anal. Calorim. 2012, 108, 25-31.

16. Uematsu, S.; Long, D. Thermography in Chronic Pain Medical Thermography, Theory and Clinical Applications; Brentwood Publishing: Los Angeles, CA, USA, 1976; pp. 52-67.

17. Fischer, A. The present status of neuromuscular thermography. Postgrad. Med. 1986, 79, $26-33$.

18. Herrick, R.T.; Herrick, S.K. Thermography in the detection of carpal tunnel syndrome and other compressive neuropathies. J. Hand Surg. 1987, 12, 943-949. [CrossRef] 
19. Maxel, X.; Bodnar, J.L.; Stubbe, L. Detection of carpal tunnel syndrome by infrared thermography. Mech. Ind. 2014, 15, 363-370. [CrossRef]

20. Tkáčová, M.; Foffova, P.; Hudak, R.; Švehlík, J.; Živčák, J. Medical thermography application in neuro- vascular diseases diagnostics. In Proceedings of the 2010 IEEE 8th International Symposium on Applied Machine Intelligence and Informatics (SAMI), Herlany, Slovakia, 28-30 January 2010; Volume 8, pp. 293-296.

21. Živcák, J.; Madarasz, L.; Hudak, R. Application of medical thermography in the diagnostics of Carpal Tunnel Syndrome. In Proceedings of the 2011 IEEE 12th International Symposium on Computational Intelligence and Informatics (CINTI), Budapest, Hungary, 21-22 November 2011; Volume 12, pp. 535-539.

22. Harris-Adamson, C.; A Eisen, E.; Dale, A.M.; Evanoff, B.; Hegmann, K.T.; Thiese, M.S.; Kapellusch, J.M.; Garg, A.; Burt, S.; Bao, S.; et al. Personal and workplace psychosocial risk factors for carpal tunnel syndrome: A pooled study cohort. Occup. Environ. Med. 2013, 70, 529-537. [CrossRef]

23. Law, H.-Z.; Amirlak, B.; Cheng, J.; Sammer, D.M. An Association between Carpal Tunnel Syndrome and Migraine HeadachesNational Health Interview Survey, 2010. Plast. Reconstr. Surg. Glob. Open 2015, 3, e333. [CrossRef]

24. El-Helaly, M.; Balkhy, H.H.; Vallenius, L. Carpal tunnel syndrome among laboratory technicians in relation to personal and ergonomic factors at work. J. Occup. Health 2017, 59, 513-520. [CrossRef]

25. Jerosch-Herold, C.; Houghton, J.; Blake, J.; Shaikh, A.; Wilson, E.C.; Shepstone, L. Association of psychological distress, quality of life and costs with carpal tunnel syndrome severity: A cross-sectional analysis of the PALMS cohort. BMJ Open 2017, 7, e017732. [CrossRef]

26. McCabe, S.J.; Gupta, A.; Tate, D.E.; Myers, J. Preferred Sleep Position on the Side is Associated with Carpal Tunnel Syndrome. Hand 2011, 6, 132-137. [CrossRef]

27. Sassi, S.A.; Giddins, G. Gender differences in carpal tunnel relative cross-sectional area: A possible causative factor in idiopathic carpal tunnel syndrome. J. Hand Surg. 2016, 41, 638-642. [CrossRef]

28. Thiese, M.S.; Merryweather, A.; Koric, A.; Ott, U.; Wood, E.M.; Kapellusch, J.; Foster, J.; Garg, A.; Deckow-Schaefer, G.; Tomich, S.; et al. Association between wrist ratio and carpal tunnel syndrome: Effect modification by body mass index. Muscle Nerve 2017, 56, 1047-1053. [CrossRef]

29. Zhang, D.; Collins, J.E.; Earp, B.E.; Blazar, P. Surgical Demographics of Carpal Tunnel Syndrome and Cubital Tunnel Syndrome Over 5 Years at a Single Institution. J. Hand Surg. 2017, 42, 929.e1-929.e8. [CrossRef] [PubMed]

30. Arslan, Y.; Bülbül, I.; Öcek, L.; Şener, U.; Zorlu, Y. Effect of hand volume and other anthropometric measurements on carpal tunnel syndrome. Neurol. Sci. 2017, 38, 605-610. [CrossRef] [PubMed]

31. Castro, A.D.A.; Skare, T.L.; Nassif, P.A.N.; Sakuma, A.K.; Barros, W.H. Sonographic diagnosis of carpal tunnel syndrome: A study in 200 hospital workers. Radiol. Bras. 2015, 48, 287-291. [CrossRef] [PubMed]

32. Khosrawi, S.; Kelishadi, A.; Sajadieh, S.; Badrian, H.; Haghighat, A. Prevalence of clinical findings of carpal tunnel syndrome in Isfahanian dentists. Adv. Biomed. Res. 2012, 1, 13. [CrossRef]

33. Komurcu, H.F.; Kilic, S.; Anlar, O. Relationship of Age, Body Mass Index, Wrist and Waist Circumferences to Carpal Tunnel Syndrome Severity. Neurol. Med. Chir. 2014, 54, 395-400. [CrossRef] [PubMed]

34. Moschovos, C.; Tsivgoulis, G.; Kyrozis, A.; Ghika, A.; Karachalia, P.; Voumvourakis, K.; Chroni, E. The diagnostic accuracy of high-resolution ultrasound in screening for carpal tunnel syndrome and grading its severity is moderated by age. Clin. Neurophysiol. 2019, 130, 321-330. [CrossRef]

35. Zambelis, T.; Tsivgoulis, G.; Karandreas, N. Carpal Tunnel Syndrome: Associations between Risk Factors and Laterality. Eur. Neurol. 2010, 63, 43-47. [CrossRef] [PubMed]

36. Żyluk, A.; Puchalski, P. A comparison of the results of carpal tunnel release in patients in different age groups. Neurol. Neurochir Pol. 2013, 47, 241-246. [CrossRef]

37. Geoghegan, J.M.; Clark, D.I.; Bainbridge, L.C.; Smith, C.; Hubbard, R. Risk Factors in Carpal Tunnel Syndrome. J. Hand Surg. 2004, 29, 315-320. [CrossRef] [PubMed]

38. Solmaz, V.; Yavuz, S.; Inanr, A.; Aksoy, D.; Pektaş, E.; Tekataş, A.; Kurt, S.G. Investigation of Nerve Conduction Studies of Carpal Tunnel Syndrome Cases with Different Risk Factors. J. Clin. Neurophysiol. 2017, 34, 139-143. [CrossRef] [PubMed]

39. Karne, S.S.; Bhalerao, N.S. Carpal Tunnel Syndrome in Hypothyroidism. J. Clin. Diagn. Res. 2016, 10, OC36. [CrossRef] [PubMed]

40. Campillo, Y.D.; De la Vega, E.J. Predictive model of cumulative trauma disorder by thermography. Adv. Eng. Res. State Sonora 2012, 2, 141-147.

41. Gómez, M.M. Prediction of work-related musculoskeletal discomfort in the meat processing industry using statistical models. Int. J. Ind. Ergon. 2020, 75, 102876. [CrossRef]

42. Grieco, A. Application of the concise exposure index (OCRA) to tasks involving repetitive movements of the upper limbs in a variety of manufacturing industries: Preliminary validations. Ergonomics 1988, 41, 1347-1356. [CrossRef]

43. Álvarez-Tello, M.; Casado-Mejía, R.; Praena-Fernández, J.M.; Ortega-Calvo, M. Desarrollo de un modelo predictivo para el índice de esfuerzo del cuidador. Rev. Esp. Geriatría Gerontol. 2017, 52, 15-19. [CrossRef]

44. Ammer, K. The glamorgan protocol for recording and evaluation of thermal images of the human body. Thermol. Int. 2008, 18, $125-129$.

45. Ammer, K.; Ring, F.; Diakides, N.; Bronzino, J. Standard Procedures for Infrared Imaging in Medicine. Med. Infrared Imaging 2007, 3, 22. [CrossRef] 
46. Roldan, K.E.; Piedrahita, M.A.O.; Benitez, H.D. Design and implementation of a protocol for acquisition and processing of infrared images obtained from hands. In Proceedings of the Symposium of Signals, Images and Artificial Vision-2013: STSIVA-2013, Bogota, Colombia, 11-13 September 2013; pp. 1-7.

47. Vardasca, R.; Ring, E.F.J.; Plassmann, P.; Jones, C.D.; Gabriel, J. Using clinical thermography as diagnostic complementary procedure for hand arm vibration syndrome. In Proceedings of the XII Congress of the European Association of Thermology, Porto, Portugal, 5-8 September 2012; pp. 67-74.

48. García, A. Prediction Models Using Spline for Smoothing of Hand Temperature Behavior by Thermography. Ph.D. Thesis, Autonomous University of Baja California, Mexicali, Mexico, 2019; 212p.

49. Marins, J.C.B.; Fernández-Cuevas, I.; Arnaiz-Lastras, J.; Fernandes, A.A.; Sillero-Quintana, M. Aplicaciones de la termografía infrarroja en el deporte. Int. J. Med. Sci. Phys. Act. Sport 2015, 15, 805-824.

50. Pinto, F. Anthropometric Thermal Assessment Method for Early Injuries in Athletes. Master's Thesis, Universidade do Porto, Porto, Portugal, 2014; 71p.

51. García, A.; Camargo, C.; Olguín, J.; Barreras, J.A.L. Analysis of risk for repetitive work using thermography sensory. In Advances in Human Factors and Ergonomics in Healthcare and Medical Devices; Duffy, V., Lightner, N., Eds.; Springer International Publishing: Cham, Switzerland, 2012; pp. 239-248.

52. Camargo, C.; Ordorica, J.; De La Vega, E.; Olguín, J.; López, O.; López, J. Analysis of temperature on the surface of the wrist due to repetitive movements using sensory thermography. Work 2012, 41, 2569-2575. [CrossRef] [PubMed]

53. Papež, B.J.; Palfy, M.; Turk, Z. Infrared Thermography Based on Artificial Intelligence for Carpal Tunnel Syndrome Diagnosis. J. Int. Med Res. 2008, 36, 1363-1370. [CrossRef] [PubMed]

54. Papež, B.J.; Palfy, M.; Mertik, M.; Turk, Z. Infrared Thermography Based on Artificial Intelligence as a Screening Method for Carpal Tunnel Syndrome Diagnosis. J. Int. Med Res. 2009, 37, 779-790. [CrossRef] [PubMed]

55. Palfy, M.; Papež, B.J. Diagnosis of Carpal Tunnel Syndrome from Thermal Images Using Artificial Neural Networks. In Proceedings of the Twentieth IEEE International Symposium on Computer-Based Medical Systems (CBMS'07), Maribor, Slovenia, 20-22 June 2007; Volume 20, pp. 59-64.

56. Tchou, S.; Costich, J.F.; Burgess, R.C.; Wexler, C.E. Thermographic observations in unilateral carpal. J. Hand Surg. 1992, 17, 631-637. [CrossRef]

57. Vasconcelos, J.T.S.; Paiva, Ângela, M.F.; Cavalcanti, M.F.; De Carvalho, J.F.; Bonfá, E.; Borba, E.F. Carpal tunnel syndrome and prediabetes: Is there a true association? Clin. Neurol. Neurosurg. 2015, 137, 57-61. [CrossRef]

58. Mansoor, S.; Siddiqui, M.; Mateen, F.; Saadat, S.; Khan, Z.H.; Zahid, M.; Khan, H.H.; A Malik, S.; Assad, S. Prevalence of Obesity in Carpal Tunnel Syndrome Patients: A Cross-Sectional Survey. Cureus 2017, 9, e1519. [CrossRef]

59. Mohammad, W.S. Work-related risk factors for Carpal Tunnel Syndrome among Majmaah University female touchscreen users. Pak. J. Med Sci. 2019, 35, 1221-1226. [CrossRef]

60. Ozcakir, S.; Sigirli, D.; Avsaroglu, H. High wrist ratio is a risk factor for carpal tunnel syndrome. Clin. Anat. 2018, 31, 698-701. [CrossRef]

61. Ünaldı, H.K.; Kurt, S.; Çevik, B.; Mumcuoğlu, İ; Sümbül, O. The relationship between waist circumference, wrist circumference, and body mass index in carpal tunnel syndrome. J. Turgut Ozal Med. Cent. 2015, 3, 152-157.

62. Lugay, C.; Matias, A. Predictive models of work-related musculoskeletal disorders (wmsds) among sewing machine operators in the garments industry. Asia Pac. J. Multidiscip. Res. 2015, 3, 56-64.

63. Sasikumar, V.; Binoosh, S.C.A.B. A model for predicting the risk of musculoskeletal disorders among computer professionals. Int. J. Occup. Saf. Ergon. 2020, 26, 384-396. [CrossRef]

64. Acquah, A.; D’Souza, C.; Martin, B.; Arko-Mensah, J.; Dwomoh, D.; Nti, A.; Kwarteng, L.; Takyi, S.; Basu, N.; Quakyi, I.; et al Musculoskeletal Disorder Symptoms among Workers at an Informal Electronic-Waste Recycling Site in Agbogbloshie, Ghana. Int. J. Environ. Res. Public Health 2021, 18, 2055. [CrossRef] [PubMed]

65. Falahati, M.; Dehghani, F.; Malakoutikhah, M.; Karimi, A.; Zare, A.; Rad, S.Y. Using fuzzy logic approach to predict work-related musculoskeletal disorders among automotive assembly workers. Med. J. Islamic Repub. Iran 2019, 33, 136. [CrossRef] 